\title{
In vitro evaluation of therapeutic antibodies against a SARS-CoV-2 Omicron B.1.1.529 isolate
}

\author{
Franck Touret $^{1 *}$, Cécile Baronti ${ }^{1}$, Hawa Sophia Bouzidi ${ }^{1}$ and Xavier de Lamballerie ${ }^{1}$. \\ ${ }^{1}$ Unité des Virus Émergents (UVE: Aix-Marseille University - IRD 190 - Inserm 1207), \\ Marseille, France. \\ *corresponding author: franck.touret@univ-amu.fr
}

Keywords: SARS-CoV-2; Omicron; therapeutic antibody, variant

\begin{abstract}
The emergence and rapid spread of the Omicron variant of SARS-CoV-2, which has more than 30 substitutions in the spike glycoprotein, compromises the efficacy of currently available vaccines and therapeutic antibodies. Using a clinical strain of the Omicron variant, we analyzed the neutralizing power of eight currently used monoclonal antibodies compared to the ancestral B.1 BavPat1 D614G strain. We observed that six of these antibodies have lost their ability to neutralize the Omicron variant. Of the antibodies still having neutralizing activity, Sotrovimab/Vir-7831 shows the smallest reduction in activity, with a factor change of 3.1. Cilgavimab/AZD1061 alone shows a reduction in efficacy of 15.8, resulting in a significant loss of activity for the Evusheld cocktail (42.6 fold reduction) in which the other antibody, Tixagevimab, does not retain significant activity against Omicron. Our results suggest that the clinical efficacy of the initially proposed doses should be rapidly evaluated and the possible need to modify doses or propose combination therapies should be considered.
\end{abstract}

\section{Short communication}

Since the emergence of the SARS-CoV-2 coronavirus in China in late 2019, the virus has spread worldwide, causing a major pandemic. The epidemic spread has been supported by the appearance of variants that combine increased transmissibility and antigenic escape to varying degrees. At the time of writing, we are witnessing the rapid replacement of the delta variant by a new variant, Omicron, which has a higher transmission capacity than all the previous variants, but also has substantial antigenic changes. Omicron has been first characterised in South Africa (B.1.1.529 lineage, "Weekly epidemiological update on COVID19 - 21 December 2021," n.d.) and exhibits the highest number of genomic mutations reported so far, especially in the spike glycoprotein where over 30 substitutions are present (Kumar et al., 2021). Such changes in the most important antigen of the virus, against which the neutralising humoral response is built, have the potential to significantly reduce the efficacy of both vaccines and therapeutic antibodies currently in clinical use (Malani et al., 2021; Taylor et al., 2021), as most of them were designed from the spike protein of the original SARS-CoV-2 strain (Baum et al., 2020; Cathcart et al., 2021; Jones et al., 2021; Kim et al., 2021).

In the current study, we tested the neutralising activity of a panel of COVID-19 therapeutic antibodies against a clinical strain of the Omicron variant. The ancestral D614G BavPat1 
European strain (B.1 lineage) was used as a reference to calculate the fold change between the $\mathrm{EC}_{50} \mathrm{~S}$ determined for each virus. To do this, we applied a standardised methodology for evaluating antiviral compounds against RNA viruses, based on RNA yield reduction (Delang et al., 2016; Kaptein et al., 2021; Touret et al., 2019), which has been recently applied to SARS-CoV-2 (Shannon et al., 2020; Touret et al., 2021, 2020; Weiss et al., 2021). The assay was performed in VeroE6 TMPRSS2 cells and calibrated in such a way that the cell culture supernatants were harvested (at 48 hours post infection) during the logarithmic growth phase of viral replication. The antibodies were tested in triplicate using 2-fold step-dilutions from 1000 to $0.97 \square \mathrm{ng} / \mathrm{mL}$ and from 5000 to $2.4 \mathrm{ng} / \mathrm{mL}$ for Cilgavimab and Tixagevimab alone and in combination. The amount of viral RNA in the supernatant medium was quantified by qRTPCR to determine the $50 \%$ maximal effective concentration $\left(E_{50}\right)$. Results were then compared with recent preliminary reports exploring the ability of the Omicron variant to escape neutralization by monoclonal antibodies.

We first observed a complete loss of detectable neutralizing activity for Casirivimab and Imdevimab (Roche-Regeneron), Bamlanivimab and Etesevimab (Eli-Lilly) and Regdanvimab (Celltrion) under our test conditions (Fig.1), which made it impossible to calculate $\mathrm{EC}_{50}$ (Table 1). This result is in line with previous $\mathrm{EC}_{50}$ determination reports (Aggarwal et al., 2021; Cameroni et al., 2021; Planas et al., 2021; VanBlargan et al., 2021; Xie et al., 2021) and with studies exploring the impact of amino-acid mutations in the SARS-CoV-2 spike receptor binding domain (RBD) conferring resistance to monoclonal antibodies (Dong et al., 2021; Starr et al., 2021a, 2021b).

Sotrovimab/Vir-7831 (GlaxoSmithKline and Vir Biotechnology) retains a neutralizing activity against the Omicron variant (Figure 1) with an $\mathrm{EC}_{50}$ shifting from 89 to $276 \mathrm{ng} / \mathrm{ml}$, i.e. a fold change reduction of 3.1 (Table 1) in comparison with the ancestral B.1 strain. This result is in accordance with preliminary reports (Table 1) and with data from Vir Biotechnology using a pseudotype virus harboring all Omicron spike mutations (Cathcart et al., 2021). The fact that Sotrovimab retains significant activity against the Omicron variant can be related to the fact that this antibody, which was originally identified from a SARS-CoV-1 survivor and was found to also neutralize the SARS-CoV-2 virus, does not target the Receptor Binding Motif (RBM) but a deeper and highly conserved epitope of RBD (Pinto et al., 2020).

We found no significant neutralizing activity for Tixagevimab $\left(E_{50}>5000 \mathrm{ng} / \mathrm{L}\right)$ against Omicron as described in two other studies (Table 1). Cilgavimab conserved a neutralizing activity (Fig.1) with an $\mathrm{EC}_{50}$ shifting from 93 to $1472 \mathrm{ng} / \mathrm{mL}$, i.e. a fold change reduction of 15.8, in accordance with Planas et al. (2021) (Table 1). When Cilgavimab was tested in combination with Tixagevimab, as proposed in the actual Evusheld/AZD7742 therapeutic cocktail (Mahase, 2021), the $\mathrm{EC}_{50}$ shifted from 35 to $1488 \mathrm{ng} / \mathrm{mL}$, i.e. a fold change reduction of 42.6 .

The observed decreases in activity should be seen in the context of the actual treatments given to patients. In the European Union, Sotrovimab is registered for the early treatment of infections (a single intravenous injection of $500 \mathrm{mg}$ ) and Evusheld is only registered at this stage for the prophylaxis of infection in subjects most at risk of developing severe forms of Covid-19 (150 mg Tixagevimab + $150 \mathrm{mg}$ Cilgavimab, intramuscular). We defined a neutralization unit $50\left(\mathrm{NU}_{50}\right)$, which is the amount of a given antibody needed to provide a $50 \%$ neutralization of $100 \mathrm{TCID}_{50}$ of a given strain. We then calculated the number of neutralizing units present in each actual treatment proposed, based on the $\mathrm{EC}_{50} \mathrm{~S}$ obtained previously, expressed in millions of neutralization units 50 per treatment ( $\mathrm{MNU}_{50}$, Table 2).

The interest of this simulation is that it allows a realistic comparison of the neutralizing capacity of each treatment. Thus, the neutralizing capacity of a treatment with $300 \mathrm{mg}$ of 
Evusheld against a type B.1 strain appears slightly higher than that conferred by $500 \mathrm{mg}$ of Sotrovimab (57.14 vs $37.45 \mathrm{MNU}_{50}$ ). In contrast, in the case of the Omicron variant, the neutralizing capacity of $300 \mathrm{mg}$ Evusheld is about one tenth of that conferred by $500 \mathrm{mg}$ Sotrovimab (1.3 vs $\left.12.1 \mathrm{MNU}_{50}\right)$.

The activity of Evusheld against the BavPat1 B.1 European strain (57.14 $\mathrm{MNU}_{50}$ ) is slightly higher than that expected from the simple addition of the activities of Cilgavimab and Tixagevimab (10.75 and 38.46 $\mathrm{MNU}_{50}$, respectively, i.e. $49.21 \mathrm{MNU}_{50}$ ) suggesting that if any synergistic action on different residues of the RBD exists, it is of modest magnitude. Against the Omicron strain, the activity of Evusheld (1.34 $\left.\mathrm{MNU}_{50}\right)$ is slightly higher than that of Cilgavimab alone $\left(0.68 \mathrm{MNU}_{50}\right)$, which is consistent with the loss of a large part of the activity of Tixagevimab but may denote a limited complementation effect between the two antibodies. It remains therefore to be precisely documented by in vivo experiments whether the combination of Cilgavimab and Tixagevimab is preferable in clinical treatment to the use of Cilgavimab alone.

We conclude that, against the Omicron variant and compared to previous variants, Sotrovimab $500 \mathrm{mg}$ retains a significant level of neutralizing activity. This activity is $\sim 30 \%$ of the activity of the same antibody treatment, and $\sim 20 \%$ of the activity of the Evusheld $300 \mathrm{mg}$ cocktail, against a B.1 strain. The activity of Evusheld $300 \mathrm{mg}$ against the Omicron variant is significantly reduced as it represents $\sim 10 \%$ of the activity of Sotrovimab $500 \mathrm{mg}$ against Omicron, and $\sim 2.5 \%$ of the activity of the Evusheld cocktail against a B.1 strain. It will therefore be important to rapidly evaluate the actual therapeutic efficacy of Sotrovimab 500 $\mathrm{mg}$ and Evusheld $300 \mathrm{mg}$ for the early treatment and prevention of infection with Omicron, respectively, at the doses initially proposed and to consider the possible need for dose modification or combination therapies. 

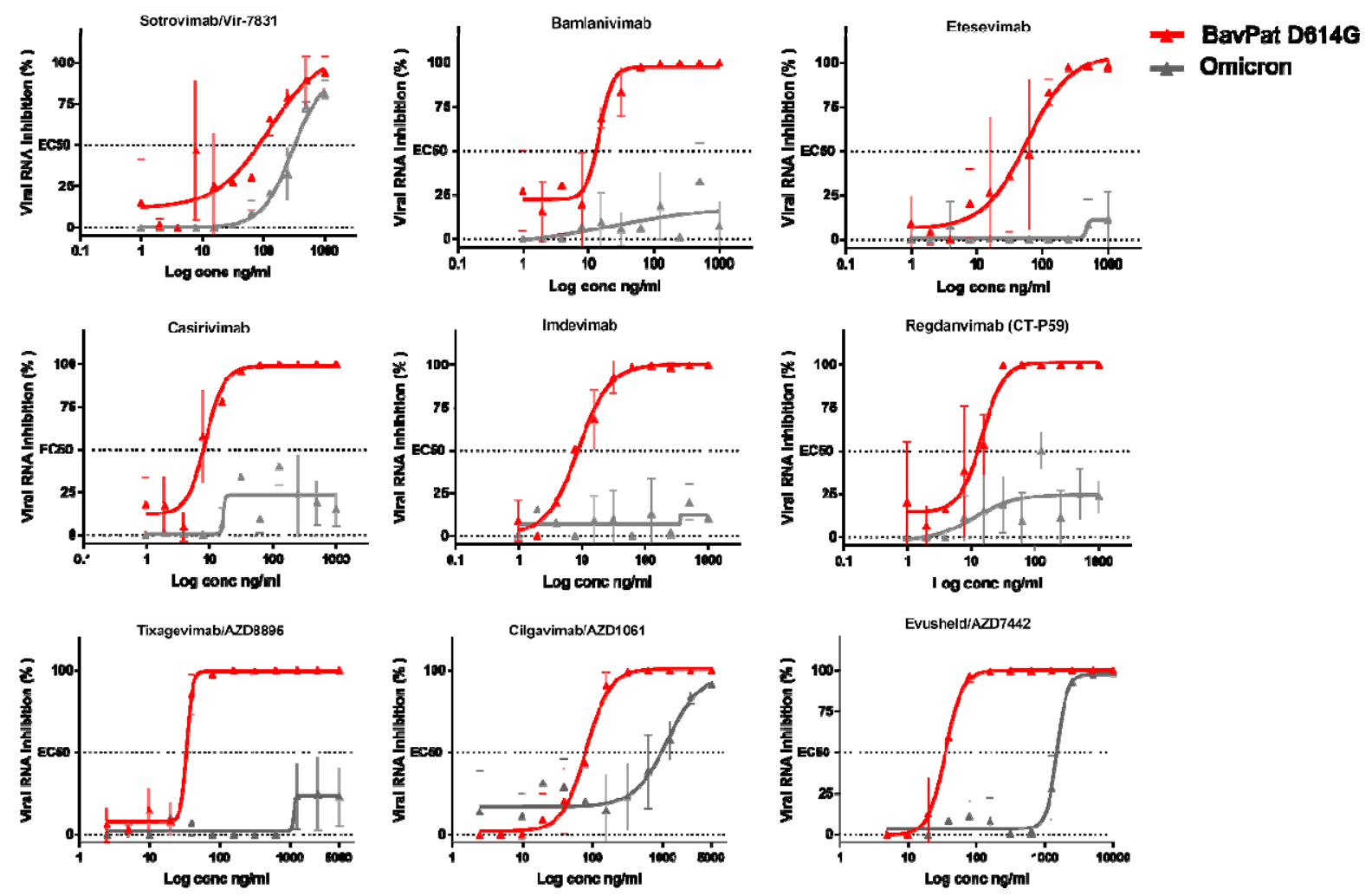

Figure 1: Dose response curves reporting the susceptibility of the SARS-CoV-2 BavPat1 D614G ancestral strain and Omicron variant to a panel of therapeutic monoclonal antibodies. Antibodies tested: Casirivimab/REGN10933, Imdevimab/REGN10987, Bamlanivimab/LYCoV555, Etesevimab/LY-CoV016, Sotrovimab/Vir-7831, Regdanvimab/CT-P59, Tixagevimab/AZD8895, Cilgavimab/AZD1061 and Evusheld/AZD7742. Data presented are from three technical replicates in VeroE6-TMPRSS2 cells, and error bars show mean \pm s.d. 
bioRxiv preprint doi: https://doi org/10.1101/2022 01.01.474639; this version posted January 3,2022. The copyright holder for this preprint (which was not certified by peer review) is the author/funder, who has granted bioRxiv a license to display the preprint in perpetuity. It is made available under aCC-BY-NC-ND 4.0 International license.

Table 1 : Interpolated $E C_{50}$ values of therapeutic antibodies against SARS-CoV-2 BavPat1 and Omicron strains. $E C_{50}$ values are expressed in $\mathrm{ng} / \mathrm{mL}$. For Sotrovimab, Cilgavimab and Tixagevimab the $E C_{50}$ is the mean of two independent experiment $(n=2)$, each including three replicates. (n.n: non-neutralising at highest concentration tested; n.t.: not tested, * antibodies were produced by the authors and are not the actual therapeutic products; \# tested using a pseudovirus-based methodology).

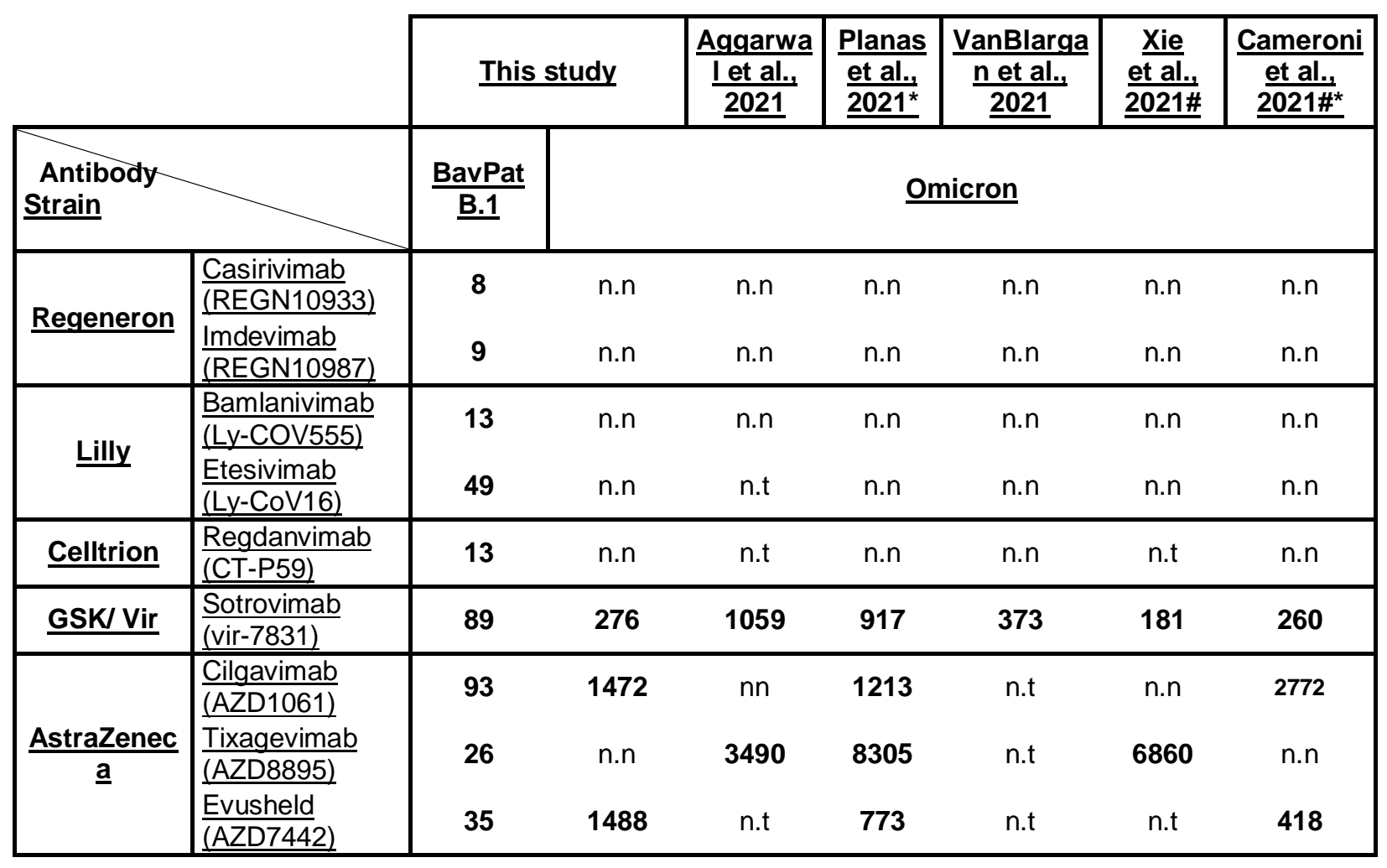


Table 2: Neutralizing capacity of Sotrovimab, Cilgavimab and Evusheld. Values are expressed in millions of neutralizing units $\left(\mathrm{MNU}_{50}\right)$ per treatment. One unit is defined as the amount of a given antibody needed to neutralize $50 \%$ of $100 \mathrm{TCI} D_{50}$ of a given strain. Doses refer to treatments authorized in the European Union (Sotrovimab: $500 \mathrm{mg} I \mathrm{~V}$ for the early treatment of infected patients (Gupta et al., 2021); Evusheld: 300 mg IM (corresponding to Cilgavimab $150 \mathrm{mg}+$ Tixagevimab $150 \mathrm{mg}$ ) for prophylaxis of infection in patients with important risk factors).

\begin{tabular}{|l|c|c|c|}
\cline { 2 - 4 } \multicolumn{1}{c|}{} & BavPat B.1 & Omicron & $\begin{array}{l}\text { Fold } \\
\text { change }\end{array}$ \\
\hline Sotrovimab/vir-7831 $(500 \mathrm{mg})$ & $\mathbf{3 7 . 4 5}$ & $\mathbf{1 2 . 0 8}$ & $\square \mathbf{3 . 1}$ \\
\hline Cilgavimab/AZD1061 $(150 \mathrm{mg})$ & $\mathbf{1 0 . 7 5}$ & $\mathbf{0 . 6 8}$ & $\square \mathbf{1 5 . 8}$ \\
\hline $\begin{array}{l}\text { Tixagevimab/AZD8895 }(150 \\
\text { mg) }\end{array}$ & $\mathbf{3 8 . 4 6}$ & n.n & - \\
\hline Evusheld/AZD7442 $(300 \mathrm{mg})$ & $\mathbf{5 7 . 1 4}$ & $\mathbf{1 . 3 4}$ & $\square \mathbf{4 2 . 6}$ \\
\hline
\end{tabular}

\section{Materials \& Methods}

Cell line

VeroE6/TMPRSS2 cells (ID 100978) were obtained from CFAR and were grown in minimal essential medium (Life Technologies) with 7].5\% heat-inactivated fetal calf serum (FCS; Life Technologies with $1 \%$ penicillin/streptomycin (PS, 5000U. $\mathrm{mL}^{-1}$ and $5000 \mu \mathrm{g} \cdot \mathrm{mL}^{-1}$ respectively; Life Technologies) and supplemented with 1 [?]\% non-essential amino acids (Life Technologies) and G-418 (Life Technologies), at $37^{\circ} \mathrm{C}$ with $5 \% \mathrm{CO}_{2}$.

\section{Antibodies}

Regdanvimab (CT-P59) was provided by Celltrion. Vir-7831 sotrovimab was provided by GSK (GlaxoSmithKline). The others antibodies: Bamlanivimab and Etesevimab (Eli Lilly and Company), Casirivimab and Imdevimab (Regeneron pharmaceuticals), Cilgavimab and Tixagevimab (AstraZeneca) were obtained from hospital pharmacy of the University hospital of La Timone (Marseille, France).

Virus strain

SARS-CoV-2 strain BavPat1 was obtained from Pr. C. Drosten through EVA GLOBAL (https://www.european-virus-archive.com/) and contains the D614G mutation.

SARS-CoV-2 Omicron (B.1.1.529) was isolated from a nasopharyngeal swab of the $1^{\text {st }}$ of December in Marseille, France. Briefly, a $12.5 \mathrm{~cm}^{2}$ culture flask of confluent VeroE6/TMPRSS2 cells was inoculated with the diluted sample. Cells were incubated at $37{ }^{\circ} \mathrm{C}$ during 6 hours after which the medium was changed with MEM medium with 5\% FCS and incubation was continued for 3 days, until a CPE appeared. Supernatant was collected, clarified by spinning at $1500 \times \mathrm{g}$ for $10 \mathrm{~min}$, supplemented with $25 \mathrm{mM}$ HEPES (Sigma), aliquoted and stored at $-80^{\circ} \mathrm{C}$. The full genome sequence has been deposited on GISAID: EPI_ISL_7899754 The strain, called 2021/FR/1514, is available through EVA GLOBAL (www.european-virus-archive.com, ref: 001V-04436)

All experiments with infectious virus were conducted in a biosafety level 3 laboratory. 


\section{EC50 determination}

One day prior to infection, $5 \times 10^{4}$ VeroE6/TMPRSS2 cells per well were seeded in $100 \mu \mathrm{L}$ assay medium (containing $2.5 \% \mathrm{FCS}$ ) in 96 well culture plates. The next day, antibodies were diluted in PBS with $1 / 2$ dilutions from 1000 to 0.97 ? $\mathrm{ng} / \mathrm{ml}$ for most of them and from 5000 to $2.4 \mathrm{ng} / \mathrm{ml}$ for Cilgavimab and Tixagevimab. Eleven 2 -fold or twelve 2 -fold (for Cilgavimab and Tixagevimab) serial dilutions of antibodies in triplicate were added to the cells $(25 \mu \mathrm{L} /$ well, in assay medium). Then, $25 \mu \mathrm{L}$ of a virus mix diluted in medium was added to the wells. The amount of virus working stock used was calibrated prior to the assay, based on a replication kinetics, so that the viral replication was still in the exponential growth phase for the readout as previously described (1-3). Four virus control wells were supplemented with $25 \mu \mathrm{L}$ of assay medium. Plates were first incubated $15 \mathrm{~min}$ at room temperature and then 2 days at $37^{\circ} \mathrm{C}$ prior to quantification of the viral genome by real-time RT-PCR. To do so, $100 \mu \mathrm{L}$ of viral supernatant was collected in S-Block (Qiagen) previously loaded with VXL lysis buffer containing proteinase $\mathrm{K}$ and RNA carrier. RNA extraction was performed using the Qiacube HT automate and the QIAamp 96 DNA kit HT following manufacturer instructions. Viral RNA was quantified by real-time RT-qPCR (GoTaq 1-step qRt-PCR, Promega) using $3.8 \mu \mathrm{L}$ of extracted RNA and $6.2 \mu \mathrm{L}$ of RT-qPCR mix and standard fast cycling parameters, i.e., $10 \mathrm{~min}$ at $50^{\circ} \mathrm{C}, 2 \mathrm{~min}$ at $95^{\circ} \mathrm{C}$, and 40 amplification cycles $\left(95^{\circ} \mathrm{C}\right.$ for $3 \mathrm{sec}$ followed by $30 \mathrm{sec}$ at $\left.60^{\circ} \mathrm{C}\right)$. Quantification was provided by four 2 log serial dilutions of an appropriate T7-generated synthetic RNA standard of known quantities $\left(10^{2}\right.$ to $10^{8}$ copies/reaction). RT-qPCR reactions were performed on QuantStudio $12 \mathrm{~K}$ Flex Real-Time PCR System (Applied Biosystems) and analyzed using QuantStudio 12K Flex Applied Biosystems software v1.2.3. Primers and probe sequences, which target SARS-CoV-2 N gene, were: Fw: GGCCGCAAATTGCACAAT; Rev: CCAATGCGCGACATTCC; Probe: FAM-CCCCCAGCGCTTCAGCGTTCTBHQ1. Viral inhibition was calculated as follow: 100* (quantity mean VC- sample quantity)/ quantity mean VC. The $50 \%$ effective concentrations (EC50 compound concentration required to inhibit viral RNA replication by $50 \%$ ) were determined using logarithmic interpolation after perorming a nonlinear regression (log(agonist) vs. response -- Variable slope (four parameters)) as previously described (2-6). All data obtained were analyzed using GraphPad Prism 7 software (Graphpad software).

\section{Funding}

This work was performed in the framework of the Preclinical Study Group of the French agency for emerging infectious diseases (ANRS-MIE). It was supported by the ANRS-MIE (BIOVAR project of the EMERGEN research programme) and by the European Commission (European Virus Archive Global project (EVA GLOBAL, grant agreement No 871029) of the Horizon 2020 research and innovation programme).

\section{Contribution}

FT and XDL conceived the experiments. XDL proposed the study. FT, CB, and HSB performed the experiments. FT, CB, HSB and XDL analyzed the results. FT and XDL wrote the paper. FT, CB, HSB and XDL reviewed and edited the paper.

\section{Acknowledgments}

We thank Pr C Drosten for providing the SARS-CoV-2 BavPat strain through EVA GLOBAL. We thank the Noemie Courtin for the technical help regarding the antiviral assay and the sequencing.

\section{Declaration of interest statement}


The authors declare that there is no conflict of interest

\section{Bibliography}

Aggarwal, A., Stella, A.O., Walker, G., Akerman, A., Milogiannakis, V., Brilot, F., Amatayakul-Chantler, S., Roth, N., Coppola, G., Schofield, P., Jackson, J., Henry, J.Y., Mazigi, O., Langley, D., Lu, Y., Forster, C., McAllery, S., Mathivanan, V., Fichter, C., Hoppe, A.C., Munier, M.L., Jack, H.-M., Cromer, D., Darley, D., Matthews, G., Christ, D., Khoury, D., Davenport, M., Rawlinson, W., Kelleher, A.D., Turville, S., 2021. SARS-CoV-2 Omicron: evasion of potent humoral responses and resistance to clinical immunotherapeutics relative to viral variants of concern (preprint). Infectious Diseases (except HIV/AIDS). https://doi.org/10.1101/2021.12.14.21267772

Baum, A., Ajithdoss, D., Copin, R., Zhou, A., Lanza, K., Negron, N., Ni, M., Wei, Y., Mohammadi, K., Musser, B., Atwal, G.S., Oyejide, A., Goez-Gazi, Y., Dutton, J., Clemmons, E., Staples, H.M., Bartley, C., Klaffke, B., Alfson, K., Gazi, M., Gonzalez, O., Dick, E., Carrion, R., Pessaint, L., Porto, M., Cook, A., Brown, R., Ali, V., Greenhouse, J., Taylor, T., Andersen, H., Lewis, M.G., Stahl, N., Murphy, A.J., Yancopoulos, G.D., Kyratsous, C.A., 2020. REGN-COV2 antibodies prevent and treat SARS-CoV-2 infection in rhesus macaques and hamsters. Science 370, 1110-1115. https://doi.org/10.1126/science.abe2402

Cameroni, E., Saliba, C., Bowen, J.E., Rosen, L.E., Culap, K., Pinto, D., VanBlargan, L.A., Marco, A.D., Zepeda, S.K., lulio, J. di, Zatta, F., Kaiser, H., Noack, J., Farhat, N., Czudnochowski, N., Havenar-Daughton, C., Sprouse, K.R., Dillen, J.R., Powell, A.E., Chen, A., Maher, C., Yin, L., Sun, D., Soriaga, L., Bassi, J., Silacci-Fregni, C., Gustafsson, C., Franko, N.M., Logue, J., lqbal, N.T., Mazzitelli, I., Geffner, J., Grifantini, R., Chu, H., Gori, A., Riva, A., Giannini, O., Ceschi, A., Ferrari, P., Cippà, P., Franzetti-Pellanda, A., Garzoni, C., Halfmann, P.J., Kawaoka, Y., Hebner, C., Purcell, L.A., Piccoli, L., Pizzuto, M.S., Walls, A.C., Diamond, M.S., Telenti, A., Virgin, H.W., Lanzavecchia, A., Veesler, D., Snell, G., Corti, D., 2021. Broadly neutralizing antibodies overcome SARS-CoV-2 Omicron antigenic shift. https://doi.org/10.1101/2021.12.12.472269

Cathcart, A.L., Havenar-Daughton, C., Lempp, F.A., Ma, D., Schmid, M.A., Agostini, M.L., Guarino, B., Di iulio, J., Rosen, L.E., Tucker, H., Dillen, J., Subramanian, S., Sloan, B., Bianchi, S., Pinto, D., Saliba, C., Culap, K., Wojcechowskyj, J.A., Noack, J., Zhou, J., Kaiser, H., Chase, A., Montiel-Ruiz, M., Dellota, E., Park, A., Spreafico, R., Sahakyan, A., Lauron, E.J., Czudnochowski, N., Cameroni, E., Ledoux, S., Werts, A., Colas, C., Soriaga, L., Telenti, A., Purcell, L.A., Hwang, S., Snell, G., Virgin, H.W., Corti, D., Hebner, C.M., 2021. The dual function monoclonal antibodies VIR-7831 and VIR-7832 demonstrate potent in vitro and in vivo activity against SARS-CoV-2 (preprint). Immunology. https://doi.org/10.1101/2021.03.09.434607

Delang, L., Li, C., Tas, A., Quérat, G., Albulescu, I.C., De Burghgraeve, T., Guerrero, N.A.S., Gigante, A., Piorkowski, G., Decroly, E., Jochmans, D., Canard, B., Snijder, E.J., Pérez-Pérez, M.J., van Hemert, M.J., Coutard, B., Leyssen, P., Neyts, J., 2016. The viral capping enzyme nsP1: a novel target for the inhibition of chikungunya virus infection. Sci. Rep. 6, 31819. https://doi.org/10.1038/srep31819

Dong, J., Zost, S.J., Greaney, A.J., Starr, T.N., Dingens, A.S., Chen, E.C., Chen, R.E., Case, J.B., Sutton, R.E., Gilchuk, P., Rodriguez, J., Armstrong, E., 
Gainza, C., Nargi, R.S., Binshtein, E., Xie, X., Zhang, X., Shi, P.-Y., Logue, J., Weston, S., McGrath, M.E., Frieman, M.B., Brady, T., Tuffy, K.M., Bright, H., Loo, Y.-M., McTamney, P.M., Esser, M.T., Carnahan, R.H., Diamond, M.S., Bloom, J.D., Crowe, J.E., 2021. Genetic and structural basis for SARS-CoV-2 variant neutralization by a two-antibody cocktail. Nat. Microbiol. 6, 1233-1244. https://doi.org/10.1038/s41564-021-00972-2

Gupta, A., Gonzalez-Rojas, Y., Juarez, E., Crespo Casal, M., Moya, J., Falci, D.R., Sarkis, E., Solis, J., Zheng, H., Scott, N., Cathcart, A.L., Hebner, C.M., Sager, J., Mogalian, E., Tipple, C., Peppercorn, A., Alexander, E., Pang, P.S., Free, A., Brinson, C., Aldinger, M., Shapiro, A.E., 2021. Early Treatment for Covid19 with SARS-CoV-2 Neutralizing Antibody Sotrovimab. N. Engl. J. Med. 385, 1941-1950. https://doi.org/10.1056/NEJMoa2107934

Jones, B.E., Brown-Augsburger, P.L., Corbett, K.S., Westendorf, K., Davies, J., Cujec, T.P., Wiethoff, C.M., Blackbourne, J.L., Heinz, B.A., Foster, D., Higgs, R.E., Balasubramaniam, D., Wang, L., Zhang, Y., Yang, E.S., Bidshahri, R., Kraft, L., Hwang, Y., Žentelis, S., Jepson, K.R., Goya, R., Smith, M.A., Collins, D.W., Hinshaw, S.J., Tycho, S.A., Pellacani, D., Xiang, P., Muthuraman, K., Sobhanifar, S., Piper, M.H., Triana, F.J., Hendle, J., Pustilnik, A., Adams, A.C., Berens, S.J., Baric, R.S., Martinez, D.R., Cross, R.W., Geisbert, T.W., Borisevich, V., Abiona, O., Belli, H.M., de Vries, M., Mohamed, A., Dittmann, M., Samanovic, M.I., Mulligan, M.J., Goldsmith, J.A., Hsieh, C.-L., Johnson, N.V., Wrapp, D., McLellan, J.S., Barnhart, B.C., Graham, B.S., Mascola, J.R., Hansen, C.L., Falconer, E., 2021. The neutralizing antibody, LY-CoV555, protects against SARS-CoV-2 infection in nonhuman primates. Sci. Transl. Med. 13, eabf1906. https://doi.org/10.1126/scitranslmed.abf1906

Kaptein, S.J.F., Goethals, O., Kiemel, D., Marchand, A., Kesteleyn, B., Bonfanti, J.F., Bardiot, D., Stoops, B., Jonckers, T.H.M., Dallmeier, K., Geluykens, P., Thys, K., Crabbe, M., Chatel-Chaix, L., Münster, M., Querat, G., Touret, F., de Lamballerie, X., Raboisson, P., Simmen, K., Chaltin, P., Bartenschlager, R., Van Loock, M., Neyts, J., 2021. A pan-serotype dengue virus inhibitor targeting the NS3-NS4B interaction. Nature. https://doi.org/10.1038/s41586021-03990-6

Kim, C., Ryu, D.-K., Lee, J., Kim, Y.-I., Seo, J.-M., Kim, Y.-G., Jeong, J.-H., Kim, M., Kim, J.-I., Kim, P., Bae, J.S., Shim, E.Y., Lee, M.S., Kim, M.S., Noh, H., Park, G.-S., Park, J.S., Son, D., An, Y., Lee, J.N., Kwon, K.-S., Lee, J.-Y., Lee, H., Yang, J.-S., Kim, K.-C., Kim, S.S., Woo, H.-M., Kim, J.-W., Park, M.-S., Yu, K.M., Kim, S.-M., Kim, E.-H., Park, S.-J., Jeong, S.T., Yu, C.H., Song, Y., Gu, S.H., Oh, H., Koo, B.-S., Hong, J.J., Ryu, C.-M., Park, W.B., Oh, M., Choi, Y.K., Lee, S.-Y., 2021. A therapeutic neutralizing antibody targeting receptor binding domain of SARS-CoV-2 spike protein. Nat. Commun. 12, 288. https://doi.org/10.1038/s41467-020-20602-5

Kumar, S., Thambiraja, T.S., Karuppanan, K., Subramaniam, G., 2021. Omicron and Delta Variant of SARS-CoV-2: A Comparative Computational Study of Spike Protein. J. Med. Virol. n/a. https://doi.org/10.1002/jmv.27526

Mahase, E., 2021. Covid-19: AstraZeneca says its antibody drug AZD7442 is effective for preventing and reducing severe illness. BMJ 375, n2860. https://doi.org/10.1136/bmj.n2860

Malani, A.N., LaVasseur, B., Fair, J., Domeier, R., Vershum, R., Fowler, R., Collins, C.D., 2021. Administration of Monoclonal Antibody for COVID-19 in Patient 
Homes. JAMA Netw. Open 4, e2129388.

https://doi.org/10.1001/jamanetworkopen.2021.29388

Pinto, D., Park, Y.-J., Beltramello, M., Walls, A.C., Tortorici, M.A., Bianchi, S., Jaconi, S., Culap, K., Zatta, F., De Marco, A., Peter, A., Guarino, B., Spreafico, R., Cameroni, E., Case, J.B., Chen, R.E., Havenar-Daughton, C., Snell, G., Telenti, A., Virgin, H.W., Lanzavecchia, A., Diamond, M.S., Fink, K., Veesler, D., Corti, D., 2020. Cross-neutralization of SARS-CoV-2 by a human monoclonal SARS-CoV antibody. Nature 583, 290-295. https://doi.org/10.1038/s41586-020-2349-y

Planas, D., Saunders, N., Maes, P., Guivel-Benhassine, F., Planchais, C., Buchrieser, J., Bolland, W.-H., Porrot, F., Staropoli, I., Lemoine, F., Péré, H., Veyer, D., Puech, J., Rodary, J., Baela, G., Dellicour, S., Raymenants, J., Gorissen, S., Geenen, C., Vanmechelen, B., Wawina-Bokalanga, T., MartíCarrerasi, J., Cuypers, L., Sève, A., Hocqueloux, L., Prazuck, T., Rey, F., Simon-Lorrière, E., Bruel, T., Mouquet, H., André, E., Schwartz, O., 2021. Considerable escape of SARS-CoV-2 Omicron to antibody neutralization. Nature d41586-021-03827-2. https://doi.org/10.1038/d41586-021-03827-2

Shannon, A., Selisko, B., Le, N.-T.-T., Huchting, J., Touret, F., Piorkowski, G., Fattorini, V., Ferron, F., Decroly, E., Meier, C., Coutard, B., Peersen, O., Canard, B., 2020. Rapid incorporation of Favipiravir by the fast and permissive viral RNA polymerase complex results in SARS-CoV-2 lethal mutagenesis. Nat. Commun. 11, 4682. https://doi.org/10.1038/s41467-020-18463-z

Starr, T.N., Czudnochowski, N., Liu, Z., Zatta, F., Park, Y.-J., Addetia, A., Pinto, D., Beltramello, M., Hernandez, P., Greaney, A.J., Marzi, R., Glass, W.G., Zhang, I., Dingens, A.S., Bowen, J.E., Tortorici, M.A., Walls, A.C., Wojcechowskyj, J.A., De Marco, A., Rosen, L.E., Zhou, J., Montiel-Ruiz, M., Kaiser, H., Dillen, J.R., Tucker, H., Bassi, J., Silacci-Fregni, C., Housley, M.P., di lulio, J., Lombardo, G., Agostini, M., Sprugasci, N., Culap, K., Jaconi, S., Meury, M., Dellota Jr, E., Abdelnabi, R., Foo, S.-Y.C., Cameroni, E., Stumpf, S., Croll, T.I., Nix, J.C., Havenar-Daughton, C., Piccoli, L., Benigni, F., Neyts, J., Telenti, A., Lempp, F.A., Pizzuto, M.S., Chodera, J.D., Hebner, C.M., Virgin, H.W., Whelan, S.P.J., Veesler, D., Corti, D., Bloom, J.D., Snell, G., 2021a. SARSCoV-2 RBD antibodies that maximize breadth and resistance to escape. Nature 597, 97-102. https://doi.org/10.1038/s41586-021-03807-6

Starr, T.N., Greaney, A.J., Addetia, A., Hannon, W.W., Choudhary, M.C., Dingens, A.S., Li, J.Z., Bloom, J.D., 2021b. Prospective mapping of viral mutations that escape antibodies used to treat COVID-19. Science 371, 850-854. https://doi.org/10.1126/science.abf9302

Taylor, P.C., Adams, A.C., Hufford, M.M., de la Torre, I., Winthrop, K., Gottlieb, R.L., 2021. Neutralizing monoclonal antibodies for treatment of COVID-19. Nat. Rev. Immunol. 21, 382-393. https://doi.org/10.1038/s41577-021-00542-x

Touret, F., Baronti, C., Goethals, O., Van Loock, M., de Lamballerie, X., Querat, G., 2019. Phylogenetically based establishment of a dengue virus panel, representing all available genotypes, as a tool in dengue drug discovery. Antiviral Res. https://doi.org/10.1016/j.antiviral.2019.05.005

Touret, F., Driouich, J.-S., Cochin, M., Petit, P.R., Gilles, M., Barthélémy, K., Moureau, G., Mahon, F.-X., Malvy, D., Solas, C., de Lamballerie, X., Nougairède, A., 2021. Preclinical evaluation of Imatinib does not support its use as an antiviral drug against SARS-CoV-2. Antiviral Res. 193, 105137. https://doi.org/10.1016/j.antiviral.2021.105137 
Touret, F., Gilles, M., Barral, K., Nougairède, A., van Helden, J., Decroly, E., de Lamballerie, X., Coutard, B., 2020. In vitro screening of a FDA approved chemical library reveals potential inhibitors of SARS-CoV-2 replication. Sci. Rep. 10, 13093. https://doi.org/10.1038/s41598-020-70143-6

VanBlargan, L.A., Errico, J.M., Halfmann, P., Zost, S.J., Crowe, J.E., Purcell, L.A., Kawaoka, Y., Corti, D., Fremont, D.H., Diamond, M., 2021. An infectious SARS-CoV-2 B.1.1.529 Omicron virus escapes neutralization by several therapeutic monoclonal antibodies (preprint). Microbiology. https://doi.org/10.1101/2021.12.15.472828

Weekly epidemiological update on COVID-19 - 21 December 2021 [WWW Document], n.d. URL https://www.who.int/publications/m/item/weeklyepidemiological-update-on-covid-19---21-december-2021 (accessed 12.26.21).

Weiss, A., Touret, F., Baronti, C., Gilles, M., Hoen, B., Nougairède, A., Lamballerie, X. de, Sommer, M.O.A., 2021. Niclosamide shows strong antiviral activity in a human airway model of SARS-CoV-2 infection and a conserved potency against the Alpha (B.1.1.7), Beta (B.1.351) and Delta variant (B.1.617.2). PLOS ONE 16, e0260958. https://doi.org/10.1371/journal.pone.0260958

Xie, X., Cao, Y., wang, jing, Jian, F., Xiao, T., Song, W., Yisimayi, A., Li, T., Yu, Y., Wang, Yao, Wang, J., Niu, X., Wang, P., An, R., Liang, H., Sun, H., Yang, S., Cui, Q., Liu, S., Du, S., Zhang, Z., Shao, F., Huang, W., Xiao, J., Wang, Youchun, Wang, X., Yang, X., Li, Q., Hao, X., Ronghua, J., 2021. B.1.1.529 escapes the majority of SARS-CoV-2 neutralizing antibodies of diverse epitopes (preprint). In Review. https://doi.org/10.21203/rs.3.rs-1148985/v1 